\title{
5-HIAA induces neprilysin to ameliorate pathophysiology and symptoms in a mouse model for Alzheimer's disease
}

\author{
Christian Klein, Guy Roussel, Susana Brun, Cristina Rusu, Christine Patte-Mensah ${ }^{\dagger}$, Michel Maitre ${ }^{* \dagger}$ (D) \\ and Ayikoe-Guy Mensah-Nyagan ${ }^{*+}$
}

\begin{abstract}
Serotoninergic activation which decreases brain A peptides is considered beneficial in mouse models for Alzheimer's disease (AD), but the mechanisms involved remain unclear. Because growing evidence suggested that the stimulation of proteases digesting $A \beta$, especially the endopeptidase neprilysin (NEP) may be effective for AD therapy/prevention, we explored the involvement of serotonin precursors and derivatives in NEP regulation. We found that 5-hydroxyindolacetic acid (5-HIAA), the final metabolite of serotonin, considered until now as a dead-end and inactive product of serotonin catabolism, significantly reduces brain A $\beta$ in the transgenic APPSWE mouse model for AD-related A $\beta$ pathology and in the phosphoramidon-induced cerebral NEP inhibition mouse model. 5-HIAA treatment improves memory performance in APPSWE mice. Furthermore, 5-HIAA and its precursors increase NEP level in vivo and in neuroblastoma cells. Inhibition of ERK 1/2 cascade by 5-HIAA or SCH772984 enhanced NEP levels, suggesting MAP-kinase pathway involvement in 5-HIAAinduced regulation of NEP expression. Our results provide the first demonstration that 5-HIAA is an active serotonin metabolite that increases brain A $\beta$ degradation/clearance and improves symptoms in the APPSWE mouse model for AD.
\end{abstract}

Keywords: Alzheimer's disease, Neprilysin, Aß peptides, 5-HIAA, Serotonergic transmission, ERK and GSK-3 pathways

\section{Introduction}

Alzheimer's disease (AD) is a multifactorial neurodegenerative disorder resulting from proteinopathies characterized by the accumulation/ aggregation of $\beta$ amyloid peptides $(\mathrm{A} \beta)$ and hyperphosphorylation followed by aggregation of microtubule-associated protein Tau $[48,52]$. Before the symptomatic expression of the disease, a long incubation time over decades is characterized by microinflammation, vasculopathy, metabolic disturbances that favorize the appearance of neurodegenerative processes in aged population. Alterations of the genes encoding amyloid precursor protein (APP), presenilin-1 or 2 (PS1 or PS2), Adamalysin 10 or Apolipoprotein E4 (APOE4) are frequent in familial $\mathrm{AD}[12]$, but the large majority of AD patients show increased brain levels of neurotoxic

\footnotetext{
* Correspondence: maitre@unistra.fr; gmensah@unistra.fr

${ }^{+}$Christine Patte-Mensah, Michel Maitre and Ayikoe-Guy Mensah-Nyagan contributed equally to this work.

Biopathologie de la Myéline, Neuroprotection et Stratégies Thérapeutiques, INSERM U1119, Fédération de Médecine Translationnelle de Strasbourg (FMTS), Université de Strasbourg, Bâtiment 3 de la Faculté de Médecine, Strasbourg, France
}

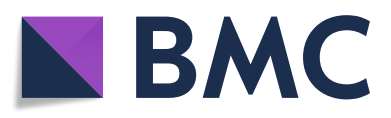

(c) The Author(s). 2018 Open Access This article is distributed under the terms of the Creative Commons Attribution 4.0 International License (http://creativecommons.org/licenses/by/4.0/), which permits unrestricted use, distribution, and reproduction in any medium, provided you give appropriate credit to the original author(s) and the source, provide a link to the Creative Commons license, and indicate if changes were made. The Creative Commons Public Domain Dedication waiver (http://creativecommons.org/publicdomain/zero/1.0/) applies to the data made available in this article, unless otherwise stated.

$\mathrm{A} \beta$ without changes of the gene aforementioned. In aged patients, it is postulated that various accumulated mutations determine or favor deleterious proteinopathies, the most frequent being an anomaly in the synthesis or elimination of amyloid peptides [41]. This in turn initiates a cascade of post-translational disturbances, including mainly the hyperphosphorylation and accumulation of Tau. These events produce an early symptomatology made of significant memory and cognitive impairment, generally accompanied by measurable brain atrophy due to neurodegeneration [49].

Several approaches have been proposed to limit $A \beta$ synthesis or to increase their elimination [2]. To reach this goal, the potentiation of some protease activities able to disaggregate pathologic $A \beta$ substrates has been studied since several years. Among possible proteolytic enzymes, the most promising seems to be neprilysin (NEP) [39]. This enzyme belongs to the family of human M13 zinc-dependent endopeptidases which cleave a wide spectrum of brain regulatory peptides, including $A \beta$ peptides [36]. Hyper-expression of NEP gene in the 
brain of transgenic mouse models for $\mathrm{AD}$ decreases the incidence of amyloid pathology, and NEP activity is age dependently reduced in the rodent and human brain [2].

Besides the genetic manipulation of NEP expression, pharmacological approaches used to modulate NEP activity revealed that somatostatin and various polyphenols up-regulate NEP activity in the brain [44]. Epigenetic mechanisms via HDAC inhibition also seem to be a strategy to potentiate brain NEP expression and to protect against AD progression [35]. Valproic acid and gammahydroxybutyrate for example have been reported to decrease brain $A \beta$ concentration, ameliorating in parallel memory performance in mouse models for $\mathrm{AD}[28,51]$.

In this context, it is known that several metabolites of tryptophan pathways through kynurenine or serotonin metabolism are implicated in neuroprotection, regulation of brain $A \beta$ levels, excitotoxicity, cognitive and synaptic maintenance [30]. Thus, several metabolites of kynurenine and serotonin pathways are suspected to be involved in AD-related neurodegenerative processes. However, the balance between these two pathways seems to be regulated by numerous factors among which neuroinflammation may promote the kynurenine pathway and in parallel impact serotonin synthesis. Because several indications favor a role of SSRI and serotonin receptors in $\mathrm{AD}$ pathophysiology and progression in human and animal models [24], we examined the possible interference of serotonin intermediates on brain $A \beta$ clearance and evidenced a specific role for 5-HIAA which is generally thought to be a dead-end and inactive product of serotonin catabolism. To strengthen our investigations and consolidate our findings, we have used two different experimental models, namely the transgenic APPSWE mouse model for AD-related A $\beta$ pathology (Tg2576) and the mouse model of phosphoramidon-evoked brain NEP inhibition [17, 20-22, 54].

\section{Materials and methods \\ In vitro experiments \\ Cell culture}

Human neuroblastoma SH-SY5Y cells and human neuroblastoma SH-SY5Y-APPwt cells stably transfected with DNA constructs harboring human wild-type APP695 (APPwt) were maintained in a humidified atmosphere of $95 \%$ air and $5 \% \mathrm{CO}_{2}$ at $37{ }^{\circ} \mathrm{C}$ [28]. Cells were seeded into plates or $100 \mathrm{~mm}$ dishes in Dulbecco modified Eagle medium, supplemented with 10\% (vol/ vol) fetal bovine serum, $100 \mathrm{U} / \mathrm{mL}$ penicillin, $100 \mu \mathrm{g} / \mathrm{mL}$ streptomycin (Fisher Scientific, France) and for the transfected cells with $300 \mu \mathrm{mg} / \mathrm{mL}$ hygromycin (Sigma-Aldrich, France), a selective antibiotic. Between 70 and $90 \%$ confluency, cells were incubated during various time periods and/or with various concentrations of compounds to be tested.

\section{RNA isolation and quantitative PCR}

Total RNA was extracted from SH-SY5Y cells after 0, 30, 60 and $90 \mathrm{~min}$ of treatment with $30 \mu \mathrm{M} 5$-HIAA, using the Nucleospin RNA L protocol (Macherey-Nagel, Düren, Germany). This protocol included a treatment of isolated RNA by DNase I. Integrity and purity of RNA was checked by spectrophotometry.

Reverse transcription was performed with $1 \mu \mathrm{g}$ RNA using Biorad iScript ${ }^{\oplus}$ cDNA synthesis kit. q-PCR was performed in an iCycler thermal cycler (Biorad, Hercules, CA, USA) using SYBR Green dye (iQ SYBR green Supermix, Biorad). For each sample, the reaction mix was a make-up of $320 \mathrm{nM}$ forward primer (F), 320 $\mathrm{nM}$ reverse primer (R), $200 \mathrm{nM}$ probe, and $4 \mu \mathrm{L}$ cDNA template in a total reaction volume of $20 \mu \mathrm{l}$ [3]. Using the iCycler iQ optical system software (version 3.1, Bio-Rad), a standard curve based on successive cDNA dilutions was performed and was used to calculate starting quantities. To ensure a thorough calculation, starting quantities of genes of interest were reported to those of a housekeeping gene (U6 or Actin) in the same plate.

All samples were analyzed in triplicates, and the mean and standard deviation were calculated. After each q-PCR, specificity of the amplification was controlled by a melting curve ranging from 55 to $95{ }^{\circ} \mathrm{C}$ whereby a single peak corresponding to the amplicon was present.

The following primer pairs were used to amplify cDNAs after reverse transcription experiments [26]:

\begin{tabular}{ll}
\hline Gene & Primer \\
\hline Neprilysin & F 5'-CCTGGAGATTCATAATGGATCTTGT-3' \\
& R 5'-AAAGGGCCTTGCGGAAAG-3' \\
U6 & F 5'-CTCGCTTCGGCAGCACA-3' \\
& R 5'-AACGCTTCACGAATTGCGT-3' \\
Actin & F 5'-CGCAGCAGTCAGGGACATTT-3' \\
& R 5'-TTCACATACAGCTTGGGAAGC-3' \\
\hline
\end{tabular}

\section{Measurement of neprilysin protein level}

SH-SY5Y cells were washed with PBS and homogenized with lysis buffer containing a protease inhibitor cocktail (Sigma-Aldrich). The proteins in whole cell lysates were quantified using the BCA protein assay kit with BSA as a standard (Pierce, Rockford, IL, USA).

NEP protein levels were measured by using a DuoSet ELISA kit (R\&D Systems Europe, Oxford, UK) according to the manufacturer's guidelines with minor modifications. Goat anti-human NEP $(1.6 \mathrm{mg} / \mathrm{mL})$ diluted in PBS ( $\mathrm{pH} 7.4$ ) was coated overnight on a high-binding 96 well plate (R\&D Systems Europe) at room temperature (RT). The plates were washed 3 times in PBS containing 0.5\% 
Tween-20 (Sigma-Aldrich) (PBS-T). Non-specific binding of antibody was blocked by addition of PBS completed with $1 \%$ Bovine serum albumin (Sigma-Aldrich) (1\% PBS-BSA) for $3 \mathrm{~h}$ at RT, then the plates were washed a further 3 times. Serial dilutions of recombinant human NEP or crude homogenates diluted in 1\% PBS-BSA or $1 \%$ PBS-BSA alone as a control were incubated for $2 \mathrm{~h}$ with continuous shaking at RT. After a further 3 washes, biotinylated anti-NEP $(1.6 \mathrm{mg} / \mathrm{mL})$ was added for $2 \mathrm{~h}$ before another wash and incubation with streptavidin-peroxidase (1200) for $20 \mathrm{~min}$ in the dark. Substrate solution (tetramethyl benzidine; R\&D Systems, Europe) was added for $30 \mathrm{~min}$, and the optical density for each well was read at $450 \mathrm{~nm}$ and $540 \mathrm{~nm}$ or $570 \mathrm{~nm}$ in a plate reader (Elisa reader model Sigma 960, Metertech, Taipei, Taiwan).

The NEP protein levels were interpolated from the standard curve generated from serial dilutions of recombinant human NEP (R\&D Systems Europe). Each measurement was repeated on 3 occasions, and the average value was calculated.

\section{Cell treatment with precursors or inhibitors of the serotonin pathway}

Different concentrations (0 to $100 \mu \mathrm{M})$ of 5-HIAA, 5-HTP, Serotonin hydrochloride (5-HT, Sigma-Aldrich) and Tryptophan (Trp, Sigma-Aldrich), were used. Pharmacological treatments were performed with specific inhibitors ((S)-(-)-carbidopa monohydrate (Abcam, Cambridge, UK), tranylcypromine hydrochloride (2-PCPA, Abcam), clorgyline hydrochloride (Abcam) were added to the SH-SY5Y cells 90 min or $24 \mathrm{~h}$ before harvest.

ERK inhibitor SCH772984 (Carbosynth, Compton Berkshire, UK), MEK 1/2 inhibitor GSK 1120212 (Targetmol, USA) or GSK-3 inhibitor CHIR99021 (Sigma-Aldrich, France) was added $30 \mathrm{~min}$ before the measurement of NEP protein.

\section{SH-SY5Y-APP cell treatment and Western blot analysis}

According to experimental design [26], the SH-SY5Y cells were incubated either with $10 \mathrm{mM}$ ammonium chloride $\left(\mathrm{NH}_{4} \mathrm{Cl}\right.$, Sigma-Aldrich) or $30 \mu \mathrm{M}$ 5-HIAA (Sigma-Aldrich) for $24 \mathrm{~h}$. Non-treated cells were used as control. After $24 \mathrm{~h}$ of treatment, the cells were rinsed twice with cold PBS pH 7.4, harvested and pelleted by centrifugation. The cell's pellets were lysed in RIPA buffer (10 mM Tris/HCl pH 8.0, $150 \mathrm{mM} \mathrm{NaCl}, 1 \%$ (vol/vol) Nonidet P-40, 0.5\% (wt/vol) sodium deoxycholate, $5 \mathrm{mM}$ EDTA) with complete inhibitor mix from Roche diagnostics (Basel, Switzerland) at $0{ }^{\circ} \mathrm{C}$ for $20 \mathrm{~min}$. The lysates were homogenized through 21-G needles 10 times, and then clarified by centrifugation at $2800 \mathrm{x}$ g for 10 min. Protein concentration of lysates was determined using a BCA protein assay kit.
A total of $50 \mu \mathrm{g}$ proteins were fractionated by $4-20 \%$ TGX SDS polyacrylamide gels (BioRad, Hercules, CA, USA). After electrotransfer to polyvinylidene fluoride membranes (BioRad), these membranes were blocked overnight at $4{ }^{\circ} \mathrm{C}$ in Tris-buffered saline (TBS: $50 \mathrm{mM}$ Tris, $150 \mathrm{mM}$ $\mathrm{NaCl}$ ) containing $0.1 \%$ (vol/vol) Tween-20 (Sigma-Aldrich) (TBS-T) and 5\% (wt/vol) skimmed milk powder. Membranes were incubated $2 \mathrm{~h}$ at RT with primary antibodies, Rabbit antibody against anti-APP C-terminal fragment (APP intracellular domain, AICD, Sigma-Aldrich) and Mouse monoclonal anti- $\beta$-actin antibody (Sigma-Aldrich) (1: 1000 and 1: 5000, respectively). After washing 3 times with TBS-T, the membranes were probed with corresponding peroxidase conjugated secondary antibodies rabbit anti-mouse or goat anti-rabbit (Abliance former Paris, France) (1: 4000) at RT for $1 \mathrm{~h}$. Detection was carried out by using a chemiluminescence detection kit (Clarity Western ECL substrate, Biorad). After washing steps, signals were detected with ChemiDoc MP (Biorad).

The relative intensity of bands was densitometrically determined by Image J software 1.46r (NIH, USA). For statistical analysis, all data from 3 independent experiments were expressed as the ratio to optical density values of the corresponding $\beta$-actin control [53]. The values were expressed as a percentage of the control group arbitrarily set at $100 \%$. The statistical analysis was done with a Student t-test.

Fluorescence-activated cell sorting (FACS) by flow cytometry After $24 \mathrm{~h}$ of treatment with $100 \mu \mathrm{M}$ 5-HIAA, SH-SY5Y cells were harvested, centrifuged for $10 \mathrm{~min}$ at $1000 \mathrm{x} \mathrm{g}$ at RT and re-suspended with $0.5 \%$ PBS-BSA before being gently fixed in $4 \%$ paraformaldehyde (PFA, Sigma-Aldrich) in PBS for $1 \mathrm{~h}$. Thereafter, the cells were submitted to two centrifugation steps $(10 \mathrm{~min}$ at $1000 \mathrm{x} \mathrm{g})$ separated by a washing step using $0.5 \%$ PBS-BSA. Cells were then incubated in permeabilization buffer $(0.1 \%$ Triton X-100 in $0.1 \%$ sodium citrate) for $2 \mathrm{~min}$ on ice. An additional round of washing and centrifugation was performed before incubating the cells with anti-NEP antibody (Merck-Millipore; 1:200) in PBS for $25 \mathrm{~min}$ at $4{ }^{\circ} \mathrm{C}$. At the end of the incubation, the cells were washed and centrifuged again for 10 $\mathrm{min}$ at $1000 \mathrm{x}$ g. Supernatants were removed and the pellets were suspended and incubated with a secondary antibody for $25 \mathrm{~min}$ at $4{ }^{\circ} \mathrm{C}$. The cells were washed and centrifuged a last time, the supernatants were removed, and the pellets were suspended in PBS before being analyzed.

\section{Proteome profiler Phospho-MAPK array}

After $1 / 2$ hour of treatment with $100 \mu \mathrm{M} 5$-HIAA or without treatment, SH-SY5Y cells were harvested, centrifuged for $5 \mathrm{~min}$ at $300 \mathrm{x}$ g at RT, and then solubilized at $1 \times 10^{7}$ cells $/ \mathrm{ml}$ in the Lysis Buffer provided with the kit for $1 / 2$ hour. The level of phosphorylation was determined 
by using a Proteome Profiler Antibody Kit (Human Phospho-MAPK Array Kit, R\&D Systems Europe, Oxford, UK). Briefly, two nitrocellulose membranes, containing 26 different capture antibodies printed in duplicate, were blocked for $1 \mathrm{~h}$ under agitation at RT. During the same time, the protein extracts were incubated with a detection antibody cocktail. After one hour, the blocking buffer was replaced by the mix protein extract - antibody cocktail and incubated overnight at 2-8 ${ }^{\circ} \mathrm{C}$ under agitation. Then the membranes were washed 3 times in wash buffer, and were put in a solution of Streptavidin-HRP for $1 / 2$ hour under agitation at RT. After a further 3 washes, the membranes were covered with a Chemi-reagent mix for 1 min before detection of the signal with ChemiDoc MP (Biorad). The relative intensity of bands was densitometrically determined by Image J software 1.46r (NIH, USA).

\section{Neprilysin activity assay}

SH-SY5Y cells were harvested and washed with PBS after $0,30,60$ and $90 \mathrm{~min}$ of treatment with $30 \mu \mathrm{M}$ 5-HIAA (Sigma-Aldrich). The cells were then sonicated in iced Tris buffer $(50 \mathrm{mM}$ Tris- $\mathrm{HCl}, \mathrm{pH} 7.4)$ and store at $-80^{\circ} \mathrm{C}$.

Measurement of neprilysin activity was performed according to the technical details given by the manufacturer for the fluorescent SensoLyte 520 kit (AnaSpec Inc., Fremont, CA, US). Briefly, $100 \mu \mathrm{g}$ of total protein were placed in the wells of a non-binding 96-well plate (Corning) before adding the substrate working solution. The reagents were mixed by shaking the plate gently for $30 \mathrm{~s}$ and the fluorescence signal was immediately measured at $\mathrm{Ex} / \mathrm{Em}=490 \mathrm{~nm} / 520 \mathrm{~nm}$ continuously and the data were recorded every $5 \mathrm{~min}$ for $1 \mathrm{~h}$.

The initial reaction velocity was determined by the slope of the linear portion of the data plot and the results were expressed in percentage by reference to control condition.

\section{Immunocytochemistry}

Coverslips were prepared with SH-SY5Y cells treated or not by 5 -HIAA at a concentration of $100 \mu \mathrm{M}$. The cells were fixed in 4\% PFA for $15 \mathrm{~min}$ and then permeabilized with $100 \%$ ethanol for $5 \mathrm{~min}$ and incubated in PBS with $5 \%$ fetal bovine serum overnight at $4{ }^{\circ} \mathrm{C}$. A rabbit polyclonal anti-neprilysin antibody (Merck; 1:200) was applied for $2 \mathrm{~h}$ at RT then a pre-adsorbed Goat polyclonal anti-Mouse IgG - H\&L (Alexa Fluor ${ }^{\circ}$ 647) antibody (Abcam; 1:500) was used as secondary antibody. Coverslips were mounted in glycerol mounting medium with DAPI and $\mathrm{DABCO}^{\mathrm{m}}$ (Abcam) before microscopic analysis using a Zeiss microscope equipped for fluorescence.

\section{In vivo experiments}

\section{Animals and treatments}

Procedures involving animals and their care were conducted in compliance with a European Communities Council Directive (86/609/EEC) and under the supervision of authorized investigators. In addition, all the protocols were reviewed and approved by the Alsace Head Office of the French Department of Veterinary and Public Health Guide for the Care and Use of Laboratory Animals. Mice were individually housed per cage in a room with 12/12-h light-dark cycle. The room was maintained under constant temperature and humidity conditions. Water and food were available ad libitum.

\section{Mice models}

Two mice models were used:

- Female Swiss albino mice, 3-month-old, outbreeded, about $20 \mathrm{~g}$ (Janvier Labs, France),

- Male APPSWE hemizygote mice (B6, SJL-Tg (APPSWE) $2576 \mathrm{Kha}$, tested for heterozygous RD1, Taconic Europe, Denmark) carrying a transgene coding for the 695-amino acid isoform of human Alzheimer APP (Tg 2576) and the corresponding wild type (WT), 13-month-old. All animals were 3035 g body weight.

\section{Phosphoramidon model of NEP inhibition and $A \beta 1-40$ or A 1 1-42 quantification}

Four groups of 5 Swiss Albino mice were treated for 5 consecutive days. Group 1 received the NEP inhibitor Phosphoramidon (Peptide Institute, Osaka, Japan) each day via intranasal route. Phosphoramidon was dissolved in PBS (with $1 \mathrm{mM}$ ascorbic acid) at a concentration of 30 $\mathrm{mM}$ and was administered intranasally as previously described [28]. Group 2 was treated with 5-HIAA via intranasal route ( $24 \mu \mathrm{L}$ of a $30 \mathrm{mM}$ solution). Group 3 received PBS alone. Group 4 received both phosphoramidon and 5-HIAA.

\section{$A \beta \quad 1-40$ and $A \beta \quad 1-42$ quantification}

After 5 days of treatment, the mice were euthanized for tissue collection $2 \mathrm{~h}$ after the last administration. The brains were removed, the two hemispheres separated and immediately frozen in liquid nitrogen and stored at $-80^{\circ} \mathrm{C}$.

The tissues of one hemisphere were homogenized in 8 volumes of ice-cold guanidine buffer $(5.0 \mathrm{M}$ guanidine$\mathrm{HCl} / 50 \mathrm{mM}$ Tris- $\mathrm{HCl}, \mathrm{pH} 8.0)$. Homogenates were mixed for $3-4 \mathrm{~h}$ at RT. The quantification of total proteins was done with a BCA protein assay kit (Pierce, Rockford, IL, USA). The lysates were then aliquoted and stored at $-80^{\circ} \mathrm{C}$ until quantification of $\mathrm{A} \beta 1-40$ and 142 peptides, according to the technical details given by 
the manufacturer (Fisher former Invitrogen, Carlsbad, CA, USA).

Samples were briefly diluted with cold Reaction buffer and centrifuged at $16,000 \mathrm{~g}$ for $20 \mathrm{~min}$ at $4 \mathrm{C}$. Supernatant was decanted and sample was stored on ice until use. Hundred $\mu \mathrm{L}$ of the diluted homogenates or of the $\mathrm{A} \beta$ peptide standards were incubated on the pre-coated 96-well plate for $2 \mathrm{~h}$ at RT. The plate was washed 4 times and $100 \mu \mathrm{L}$ of the primary antibody was added for $1 \mathrm{~h}$ at RT. After 4 further washes, $100 \mu \mathrm{L}$ of the secondary antibody was added for $30 \mathrm{~min}$ at RT. After 4 new washes, $100 \mu \mathrm{l}$ of Stabilized Chromogen was added to each well for $30 \mathrm{~min}$ at RT in the dark. Finally, the reaction was stopped by $100 \mu \mathrm{L}$ of Stop Solution to each well and the optical density was read at $450 \mathrm{~nm}$ in a plate reader (Elisa reader model Sigma 960, Metertech, Taipei, Taiwan).

The $\beta$ peptides levels were interpolated from the standard curve generated from serial dilutions of synthetic peptide. Each measurement was repeated on 3 occasions, and the average value was calculated.

The results were analyzed with an analysis of variance (ANOVA $p<0.0001$ ) to evaluate the effects of genotype and treatment factors. Post hoc analyses were performed with the Bonferroni test.

\section{Tg 2576 and WT mice treatment}

Two groups of mice (12 Tg 2576 and $12 \mathrm{WT}$ ) were administered daily via intra-nasal route with $4 \mu \mathrm{L}$ of a 30 $\mathrm{mM}$ solution of 5-HIAA (Sigma-Aldrich, France) in PBS [20, 21]. In parallel, 24 other animals (12 $\mathrm{Tg} 2576$ and $12 \mathrm{WT}$ ) were treated for 5 consecutive days with $48 \mathrm{mg}$ / kg 5-Hydroxy-L-tryptophan (5-HTP, Sigma-Aldrich) administrated IP. Control groups were obtained by administration of PBS (12 Tg 2576 and $12 \mathrm{WT}$ ). These mice were the used for the neprilysin activity assay or for the spatial novelty task.

\section{Neprilysin activity assay}

To measure NEP activity in the mouse brain, the animals were treated daily for 5 consecutive days and euthanized for tissue collection $2 \mathrm{~h}$ after the last administration for the Tg 2576 mouse (sub-chronical treatment) and at various times (0 to $120 \mathrm{~min}$ ) for the Swiss mice (acute treatment). The brains were removed, the two hemispheres separated and immediately frozen in liquid nitrogen and stored at $-80^{\circ} \mathrm{C}$. The tissues of one hemisphere were homogenized in 5 volumes of ice-cold PBS, centrifuged at $15000 \mathrm{x}$ g for $5 \mathrm{~min}$ at $4{ }^{\circ} \mathrm{C}$ and the supernatant was decanted and stored at $-80^{\circ} \mathrm{C}$. The quantification of total proteins was done by a $\mathrm{BCA}$ protein assay kit).

Measurement of neprilysin activity was performed according to the technical details given by the manufacturer for the fluorescent SensoLyte 520 kit (AnaSpec Inc., Fremont, CA, US). Briefly, $100 \mu \mathrm{g}$ of total protein were placed in the wells of a non-binding 96-well plate (Corning) before adding the substrate working solution. The reagents were mixed by shaking the plate gently for $30 \mathrm{~s}$ and the fluorescence signal was immediately measured at $\mathrm{Ex} / \mathrm{Em}$ $=490 \mathrm{~nm} / 520 \mathrm{~nm}$ continuously and the data were recorded every $5 \mathrm{~min}$ for $1 \mathrm{~h}$.

The initial reaction velocity was determined by the slope of the linear portion of the data plot and the results were expressed in percentage by reference to control condition.

\section{Spatial novelty task}

This task is based on the spontaneous tendency of mice to preferentially explore objects which have been displaced within a familiar arrangement of objects. Tg 2576 mice are deeply impaired in this task as early as 7 to 8 months of age, independently of the rd mutation $[38,57]$.

The spatial novelty task was performed in a square Plexiglas open field $(52 \times 52 \times 40 \mathrm{~cm})$. For each testing period, a specific set of 7 different objects ( 4 for the habituation phases and 3 for the spatial recognition task), which differed in shape, color, and materials, were used. Each object was available in duplicate (one for each trial when required) and was wiped with $70 \%$ ethanol as the whole open field between each trial. On days 1 and 2, the mice received a habituation trial of $10 \mathrm{~min}$ with 2 different objects each day.

On day 3 (5th day of treatment), the mice explored the spatial configuration of 3 new objects during a 10-min acquisition trial, returned in their home cage for $3 \mathrm{~min}$, and then received a $10-\mathrm{min}$ retention trial with a new spatial configuration resulting from the shifting of one of the 3 objects to a new location. Recognition performances were calculated as the additional time spent exploring the displaced object during the retention trial when mice are the most involved in exploring the objects. This value was compared with the 0 value (no detection of the spatial change) with a Student t-test to measure whether spatial novelty detection occurred and was also compared among groups with an analysis of variance (ANOVA $p<0.0001$ ) to evaluate the effects of genotype and treatment factors. Post-hoc analyses were performed with the Newman-Keuls test.

\section{Immunocytochemistry on brain tissue slices}

Tg 2576/APPSWE mice chronically treated with 5-HIAA were perfused through the heart with cold $4 \%$ PFA. The brains were fixed in a $4 \%$ PFA solution for $72 \mathrm{~h}$ at $4{ }^{\circ} \mathrm{C}$ and afterwards were immersed in PBS containing 20\% sucrose for $48 \mathrm{~h}$. The brains were cut in a vibratome Leica VT1000M $(80 \mu \mathrm{m}$ thick) and the slices were collected in a Watson medium. 
Floating sections were immunostained as follows: Tissue slides were rehydrated with PBS for $1 \mathrm{~h}$ at RT then blocked overnight at $4{ }^{\circ} \mathrm{C}$ with $5 \%(\mathrm{v} / \mathrm{v})$ fetal bovine serum in PBS. Sections were stirred overnight at $4 \mathrm{C}$ with the primary antibodies (mouse monoclonal Anti- $\beta$ Amyloid 1-40 antibody (Abcam) and rabbit polyclonal anti-Neprilysin antibody (Merck Millipore) at a dilution of 1:200. Sections were then washed 10 to 12 times for $1 \mathrm{~h}$ in PBS pH 7.4. Then the sections were stirred with species-specific secondary antibodies (pre-adsorbed Goat polyclonal anti-Mouse IgG - H\&L (Alexa Fluor ${ }^{\bullet}$ 647) antibody (Abcam) and pre-adsorbed Goat polyclonal anti-Rabbit IgG - H\&L (Alexa Fluor ${ }^{\odot}$ 488) antibody (Abcam), at a dilution of 1:500, overnight at $4 \mathrm{C}$ in the dark. Sections were washed again (10 to 12 times for 1 h) with PBS pH 7.4. After this second period of washing, the sections were mounted in glycerol mounting medium with DAPI and $\mathrm{DABCO}^{\mathrm{TM}}$ (Abcam) before microscopic analysis using a microscope (Zeiss Axiolmager Z2).

\section{Statistical analysis}

GraphPad Prism was used for all statistical analysis. For ANOVA multiple statistical comparisons, NewmanKeuls or Bonferroni tests were used and two-sided unpaired Student's $t$-test for single statistical comparison. Statistical distribution for the Post-hoc analyses was: ${ }^{*} p$ $<0.05, * *<<0.005$ and $* * * 0.0001$. Errors are standard error of mean (SEM).

\section{Results}

The synthesis and activity of NEP in SH-SY5Y neuronal cells increase time-dependently in the presence of graded concentrations of 5-HIAA

The serotonin catabolite 5-HIAA at a dose of $100 \mu \mathrm{M}$ increases NEP activity in SH-SY5Y cells with time. The maximum activity culminates at 90-120 min after addition of the compound and decrease to basal level 3 $\mathrm{h}$ later (Fig. 1a). Under the same conditions, the corresponding NEP mRNA messenger was measured in cell cultures until $90 \mathrm{~min}$ of incubation. An increase was noticed starting at $30 \mathrm{~min}$ and was elevated by about 30 times after $90 \mathrm{~min}$, which corresponds to the maximum of NEP activity (Fig. 1b). The neo-synthesis of NEP protein, measured in cells cultured in the presence of increased amounts of 5-HIAA by an ELISA method, showed an $\mathrm{EC}_{50}$ of $8 \pm 3 \mu \mathrm{M}$ (Fig. 1c). This concentration is within the range of 5-HIAA concentration found in brain tissue [50].

5-HIAA or 5-HTP administration in vivo increases NEP activity in the mouse brain

$\mathrm{Tg} 2576$ mice were intranasally administered either $24 \mu \mathrm{L}$ of a $30 \mathrm{mM}$ solution of 5 -HIAA or with $48 \mathrm{mg} / \mathrm{kg}$
I.P of 5-HTP consecutively for 5 days. At the end of treatment, NEP activities were measured. Both 5-HTP and 5-HIAA treatments increase the level of NEP activity in brain, the treatment with 5-HIAA being the more active (Fig. 1f). In a second series of experiments, Swiss albino mice were treated with 5-HIAA at time zero $(24 \mu \mathrm{L}$ of a $30 \mathrm{mM}$ solution) and the NEP activity was determined in brain every $30 \mathrm{~min}$ until $120 \mathrm{~min}$. A rapid increase in this activity was shown with a maximum at $90 \mathrm{~min}$, confirming in vivo the result obtained in cell cultures (Fig. 1g).

\section{Cell analysis by flow cytometry confirms the stimulatory effect of 5-HIAA on NEP expression}

The induction of NEP expression by 5 -HIAA is rapid when measured in a cell's homogenate. However, NEP protein targeting the cell membrane is a prolonged process [25]. For this reason, we confirmed the induction of NEP protein in SH-SY5Y neuronal cells using flow cytometry analysis after incubation for $24 \mathrm{~h}$ with $100 \mu \mathrm{M} 5$-HIAA. The cells were labeled with a NEP specific antibody. Figure 1d represents a qualitative analysis of the intensity of NEP antibody-induced immunolabeling in 5-HIAA-treated and control SH-SY5Y cells. A quantitative approach has been used to count cells by flow cytometry. Figure 1e shows the percentage of NEP positive cells under control conditions (46\%) and in the presence of $100 \mu \mathrm{M} 5$-HIAA (89\%).

\section{Effect of 5-HIAA in a pharmacological model of brain $A \beta$ accumulation}

Adult Swiss albino mice treated for 5 days by intranasal administrations of the NEP inhibitor phosphoramidon ( $\mathrm{K}_{\mathrm{i}}$ of about $2 \mathrm{nM}$ ) showed increased brain concentrations of both 1-40 A $\beta$ (+39\%) and 1-42 A $\beta$ (+144\%) compared to control mice treated with saline. Administration of 5-HIAA alone to healthy mice reduced brain basal levels of 1-40 and 1-42 A $\beta$ about 14 and $32 \%$, respectively. The co-treatment of phosphoramidon-receiving mice with 5-HIAA decreased the brain 1-40 A $\beta$ ($15 \%)$ and $1-42 \mathrm{~A} \beta(-45 \%)$ concentrations. These results reveal that 5-HIAA is capable of counteracting $A \beta$ accumulation in the brain under physiological or pharmacologically-evoked (phosphoramidon-induced NEP inhibition) conditions (Fig. $2 \mathrm{a}$ and $\mathrm{b}$ and Table 1).

\section{5-HIAA treatment reduces brain $A \beta$ concentration in APPSWE mice}

Tg 2576 APPSWE mice are well characterized as a model for $\mathrm{AD}$-related $\mathrm{A} \beta$ pathology expressing brain 140 and 1-42 A $\beta$ accumulations [17, 22, 54]. We measured the concentration of $1-40$ and $1-42$ A $\beta$ peptides in cerebral hemispheres of 14 months aged APPSWE mice treated (5 consecutive days) or not by intranasal 


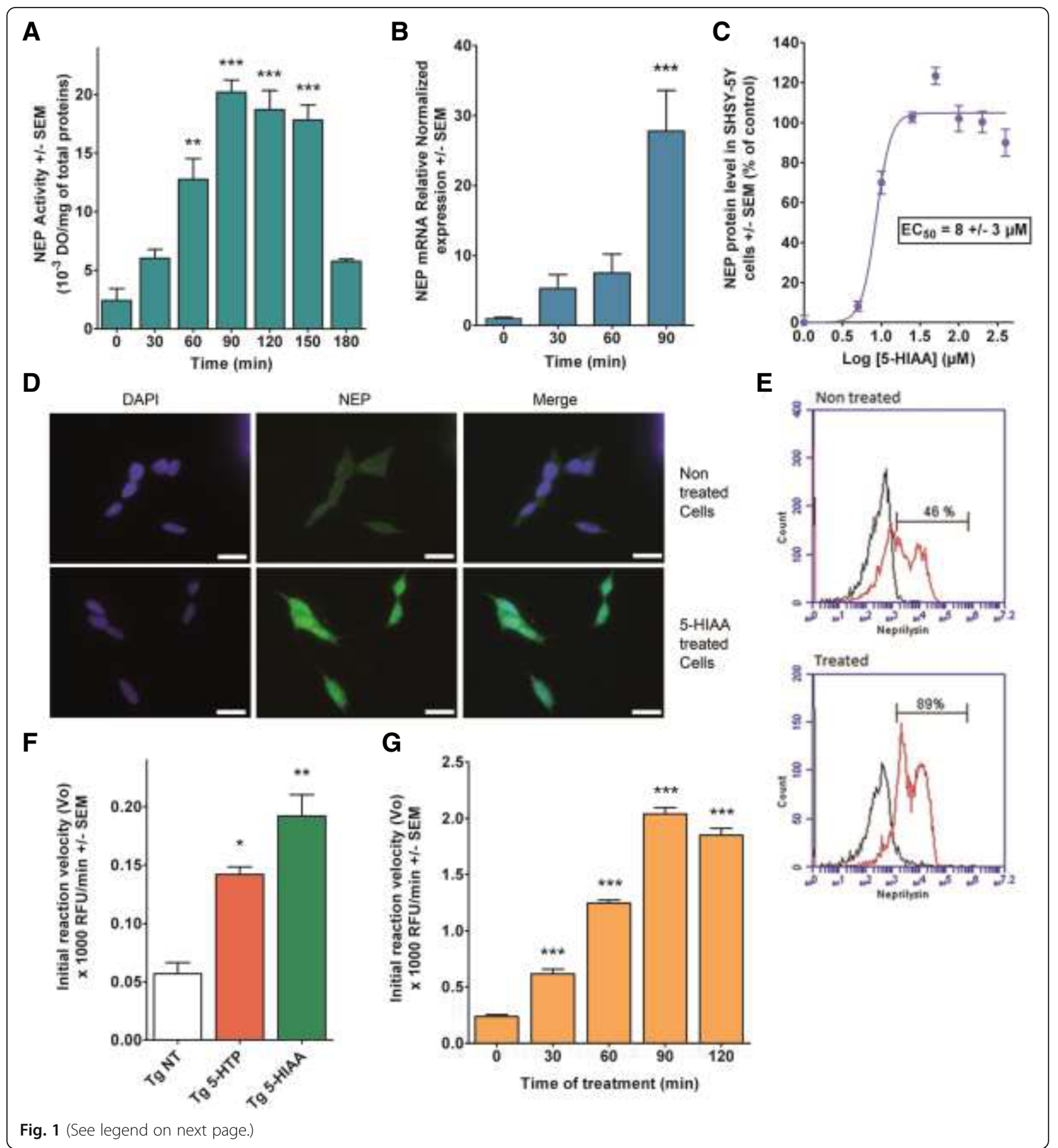


(See figure on previous page.)

Fig. 1 Effects of 5-HIAA on NEP expression and activity in SH-SY5Y neuronal cells and mouse brain. a, b, c: Experiments in SH-SY5Y neuroblastoma cells. a Kinetic of NEP activity as a function of incubation time (0 to $180 \mathrm{~min}$ ) in cells treated by $100 \mu \mathrm{M}$ 5-HIAA. NEP activity was determined with a fluorescent Sensolyte 520 kit (AnaSpec Inc., Fremont, CA, US). NEP activity culminates at 90-120 min after addition of the compound, with quantitative values corresponding to $20+/-1$ and $19+/ 210^{3} \mathrm{DO} / \mathrm{mg}$ of total proteins, respectively. These maximal values decrease to basal level after $3 \mathrm{~h}$. $\mathbf{b} \mathrm{q}-$ PCR assessment of NEP mRNA increase as a function of incubation time (0 to $90 \mathrm{~min}$ ) in SH-SY5Y cells treated by $100 \mu \mathrm{M}$ 5-HIAA. The increase of NEP mRNA level already detectable at $30 \mathrm{~min}$, reached a value 30 times higher at 90 min which represents the time point corresponding to NEP maximal activity. $\mathbf{c}$ ELISA test determination of the dose-response effect of $24 \mathrm{~h}$ 5-HIAA treatment on NEP activity. Evaluation of the effects of increasing doses of 5-HIAA showed an $\mathrm{EC}_{50}$ of $8 \pm 3 \mu \mathrm{M}$, a concentration within the range of 5-HIAA concentration found in brain tissue. The statistical analysis of triplicate samples was done by an ANOVA completed with a Bonferroni's Multiple Comparison Test. ${ }^{* *} p<0.005$, ${ }^{* *} p<0.0001$. d

Immunocytochemistry with anti-NEP antibody of SH-SY5Y cells treated with $100 \mu \mathrm{M}$ 5-HIAA for $24 \mathrm{~h}$ versus non-treated controls. Scale bars: $20 \mu \mathrm{m}$. e Fluorescence-activated cell sorting (FACS) by flow cytometry on SHSY-5Y cells treated with 5-HIAA (100 $\mu \mathrm{M})$ for $24 \mathrm{~h}$ versus controls. $46 \%$ of cells were neprilysin-positive in control cells while $89 \%$ were positively labeled in treated cells. Black curve: no secondary antibody; Red curve: cells treated with NEP secondary antibody. f, $\mathbf{g}$ : Experiments on mouse brain in vivo. f Effects of 5-HTP (48 mg/kg, I.P.) or 5-HIAA ( $24 \mu \mathrm{L}$ of a $30 \mathrm{mM}$ solution, intra-nasal) on NEP activity in 14 months APPSWE mice brain ( $n=5$ for each treatment). Drugs were administered each day during five consecutive days. Both $5-$ HTP and 5-HIAA treatments increase the level of NEP activity in brain (142+/- 7 and $192+/-18$ Relative Fluorescence Units (RFU)/min, respectively). However, 5-HIAA treatment was the most effective. $\mathbf{g}$ Kinetics of NEP enzymatic activity in 3 months Swiss Albinos mice $(n=5$ at each time point) treated by an intra-nasal administration of $24 \mu \mathrm{L}$ of a $30 \mathrm{mM}$ solution of 5-HIAA at time zero. The brain NEP activity was determined every 30 min until $120 \mathrm{~min}$. A rapid increase of NEP activity was detected at $90 \mathrm{~min}$ with a maximum value of $2040+/-50 \mathrm{RFU} / \mathrm{min}$. The statistical analysis was done by an ANOVA completed with a Bonferroni's Multiple Comparison Test. ${ }^{*} p<0.05 ;{ }^{* *} p<0.005 ;{ }^{* *} p<0.0001$ by reference to NT or time zero

5-HIAA or by 5 -HTP $(48 \mathrm{mg} / \mathrm{kg})$ injected IP. This last compound is a precursor of 5-HIAA in the brain, but also of serotonin (Fig. 3a). Six hours after the last administration of each compound, the animals were killed and brain $\mathrm{A} \beta$ concentrations were determined.

In the wild type counterparts of $\mathrm{Tg} 2576$ mice, 5-HIAA treatment reduces brain 1-40 and 1-42 A $\beta$ concentrations by 19 and 39\%, respectively. In APPSWE mice, the decrease of brain 1-40 A $\beta$ level was - 39\% and $-69 \%$ after 5 -HIAA or 5 -HTP administration while the reduction of cerebral $1-42 \mathrm{~A} \beta$ level was $-14 \%$ and $-45 \%$ after 5 -HIAA or 5 -HTP treatment, respectively (Fig. 2c and Table 2).

\section{5-HIAA or 5-HTP treatments ameliorate memory task performance in both WT and Tg 2576 APPSWE mice}

Tg 2576 APPSWE mice and their WT counterparts were treated for five consecutive days with 5-HIAA (intranasal administration) or by 5 -HTP $(48 \mathrm{mg} / \mathrm{kg}$ I.P). Six hours after the last administration, the mice were tested for spatial recognition test. WT mice treated with 5-HTP or 5-HIAA exhibited an improved performance than control animals treated with saline; 5-HIAA-treated animals showed the best performance. Non-treated $\mathrm{Tg}$ 2576 APPSWE mice performed very poorly compared to transgenic animals treated with 5-HTP or 5-HIAA under the same conditions. Retention performances of the non-treated APPSWE groups were lower than those of treated APPSWE, treated WT and non-treated WT groups respectively (Newman-Keuls: $p<0.001$, APPSWE control groups compared to each other group) (Fig. 2e).

\section{A role for 5-HIAA precursors in NEP induction?}

Tryptophan, 5-HTP and serotonin (5-HT) are the main precursors of 5-HIAA in the brain. We examined in a series of experiments the potential role of these compounds to induce NEP via the production of 5-HIAA. Tryptophan is both the precursor of kynurenic acid through the kynurenic pathway and of 5-HIAA through serotonin catabolism (Fig. 3a). Kynurenic acid has been found to be a NEP inducer and its neuroprotective properties are well documented [29]. In the presence of IMAO $(A+B)$, the induction of NEP by tryptophan is reduced by about $50 \%$, so the remaining activity of tryptophan could be due to the formation of kynurenic acid. In the absence of inhibitor, L-tryptophan possesses an $\mathrm{EC}_{50}$ of $19 \pm 2 \mu \mathrm{M}$ for the induction of NEP in SH-SY5Y cell cultures (Fig. 3b and c).

5-HTP is a well-known precursor of serotonin and of 5-HIAA in the brain. In the presence of either carbidopa, which inhibits its decarboxylation into serotonin or of tranylcypromine which blocks its transformation into 5-HIAA, the inductive capacity of 5-HTP on NEP expression is significantly reduced compared to 5 - HTP tested without inhibitors (Fig. 3c). In the presence of carbidopa, 5-HTP possesses an intrinsic activity on NEP induction with an $\mathrm{EC}_{50}$ of $5 \pm 1 \mu \mathrm{M}$ (Fig. 3b), but the maximum activity reaches a plateau at $20 \%$.

Finally, increasing doses of serotonin incubated in the presence of tranylcypromine showed no effect on NEP induction (Fig. 3b, green). Also, serotonin at $100 \mu \mathrm{M}$ exerted no significant effect on NEP expression in the presence of IMAO (Fig. 3c). Serotonin incubated alone exhibited some effect, probably because of its role as a precursor of 5-HIAA.

\section{5-HIAA induces NEP neo-expression via a MAP-kinase driven mechanism}

The level of phosphorylation of the principal intermediates of MAP-kinase pathway was determined by using 


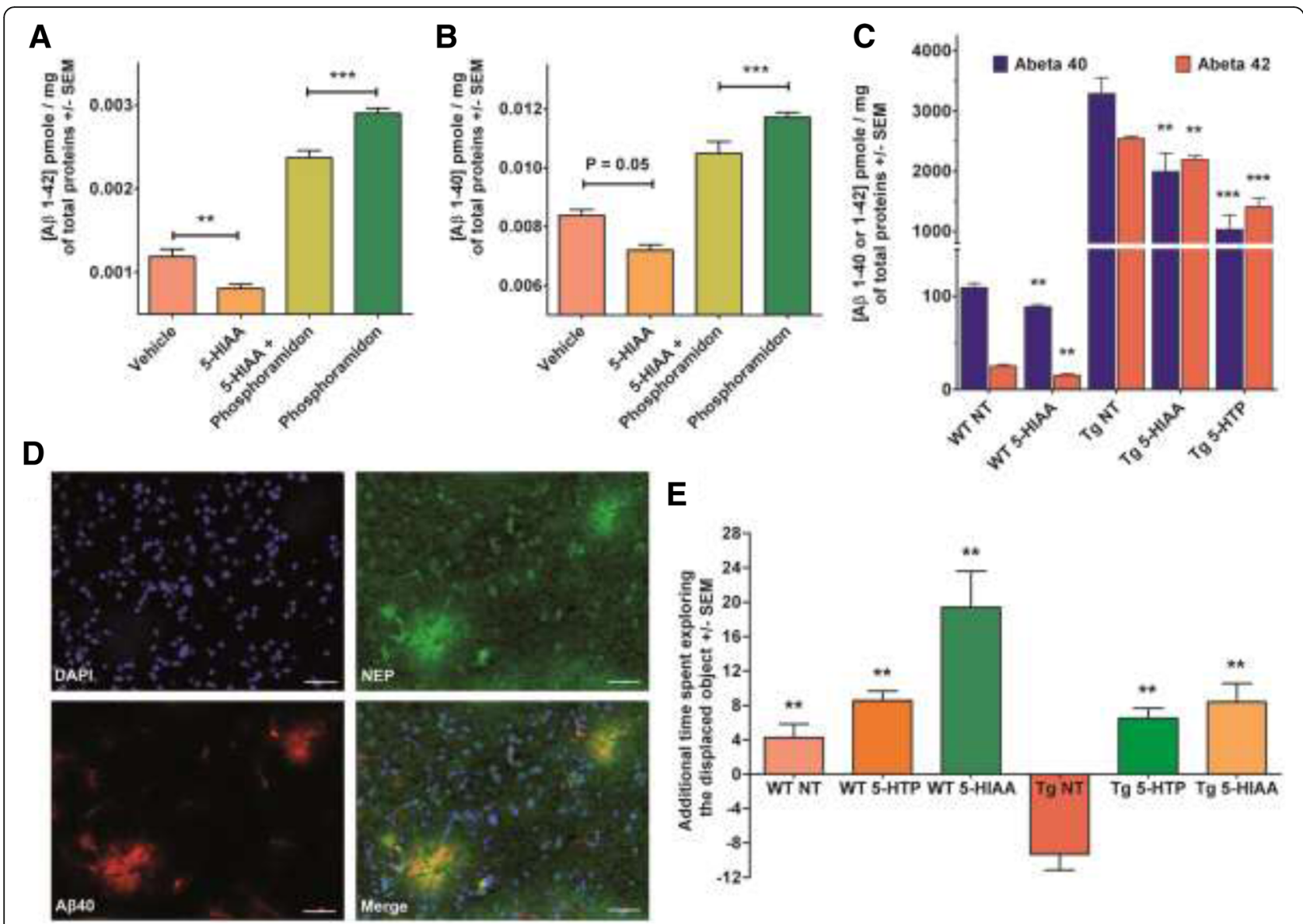

Fig. 2 Effects of 5-HIAA on brain amyloid peptide accumulation and memory performance. $\mathbf{a}$, $\mathbf{b}$ : Inhibitory action of 5-HIAA against phosphoramidoninduced brain $A \beta$ accumulation in 3-month-old Swiss albino mice ( $n=7$ for each group). a Phosphoramidon induces an increase in A $1-42$ peptide which is counteracted by 5-HIAA treatment. The effect of 5-HIAA can be seen also in control mice non-treated with Phosphoramidon (see also Table 1). Statistical analysis by an ANOVA completed with a Bonferroni's Multiple Comparison Test. ${ }^{*} p<0.05,{ }^{* *} p<0.005,{ }^{* * *} p<0.0001$. b: Same results than in A with the AB 1-40 peptide. c 5-HIAA- or 5-HTP-induced decrease of brain Aß peptide level in 14-month-old Tg 2576/APPSWE mice (Tg). The mice ( $n=7$ for each group) were treated daily during 5 consecutive days with $5-\mathrm{HTP}$ ( $48 \mathrm{mg} / \mathrm{kg}$, I.P.) or 5-HIAA (24 $\mu \mathrm{L}$ of a $30 \mathrm{mM}$, intra-nasal). 5-HIAA treatment reduces brain 1-40 and 1-42 A 3 concentrations in wild type (WT) and APPSWE mice. 5-HTP treatment is also active in APPSWE mice (see also Table 2). The statistical analysis was done by an ANOVA completed with a Bonferroni's Multiple Comparison Test of NT (non-treated) WT (wildtype) or Tg (Tg 2576/APPSWE) mice. d Photomicrographs showing the co-localization of NEP and 1-40 Aß peptide in the cortex of Tg 2576/APPSWE mice brain. Scale bars: $50 \mathrm{\mu m}$. This image is an illustration of the distribution of NEP and amyloid deposits co-localization. e Effects of 5 consecutive days intra-nasal 5-HIAA (24 $\mu$ l of a $30 \mathrm{mM}$ solution) or I.P. 5-HTP (48 mg/kg) treatments on the spatial novelty performances of 14-month-old wild-type (WT) and Tg 2576/APPSWE (Tg) mice ( $n=7$ for each group). Results are shown as the mean additional time (SEM) spent in exploring the displaced object versus the non-displaced objects during the retention trial. This value was compared to the 0 value (no detection of the spatial change) with a Student t-test $(* * 0.01)$ to determine whether spatial novelty detection occurred. Treated WT mice exhibited an improved performance compared to control animals; 5-HIAA-treated mice showed the best performance. Non-treated (NT) Tg 2576/APPSWE mice performed very poorly compared to treated transgenic animals. The various groups were compared with an ANOVA $(P<0.0001)$ completed with a Newman-Keuls Multiple Comparison Test to evaluate the effects of treatments. Retention performances of the non-treated (NT) APPSWE groups were lower than those of treated APPSWE, treated WT and non-treated WT groups, respectively

the Proteome Profiler Antibody Kit (R\&D Systems). This system detects the phosphorylation of 26 human kinases simultaneously. SH-SY5Y cells were treated during 30 min with $100 \mu \mathrm{M} 5$-HIAA and then were analyzed according to the recommended protocol. Figure 4a represents the integrated spots that were significantly different from the non-treated cells. From these results, we decided to explore particularly the ERK pathway, which appears to be down-regulated by 5 -HIAA. The modification of GSK-3 $\alpha / \beta$, a strategic factor for tau phosphorylation, was also significantly affected by the treatment, together with the transcription factor CREB. The phosphorylation of all these intermediates and transcription factor are decreased by the cell's treatment with 5-HIAA.

SCH772984 is a specific inhibitor of ERK1/2 with $\mathrm{IC}_{50}$ values of $4 \mathrm{nM}$ and $1 \mathrm{nM}$ in cell-free assays [8]. We incubated this compound alone or in combination with 
Table 1 Variations of brain amyloid peptide level in phosphoramidon-treated and control mice after 5-HIAA or vehicle treatment

\begin{tabular}{llllll}
\hline & Vehicle & 5-HIAA & Phosphoramidon & 5-HIAA + Phosphoramidon & \\
\hline A 342 & 1.2 & 0.8 & 2.9 & 2.4 & Mean (pg/total proteins) \\
& 100 & 68 & 244 & 199 & Mean compared with vehicle (\%) \\
& 0 & -32 & 144 & 99 & \% of variation compared to Vehicle \\
& -144 & -176 & 0 & -45 & \% of variation compared to Phosphoramidon \\
A 340 & 8.4 & 7.2 & 11.7 & 10.5 & Mean (pg/total proteins) \\
& 100 & 86 & 140 & 125 & Mean compared with vehicle (\%) \\
& 0 & -14 & 40 & 25 & \% of variation compared to Vehicle \\
& -39 & -54 & 0 & -15 & \% of variation compared to phosphoramidon \\
\hline
\end{tabular}

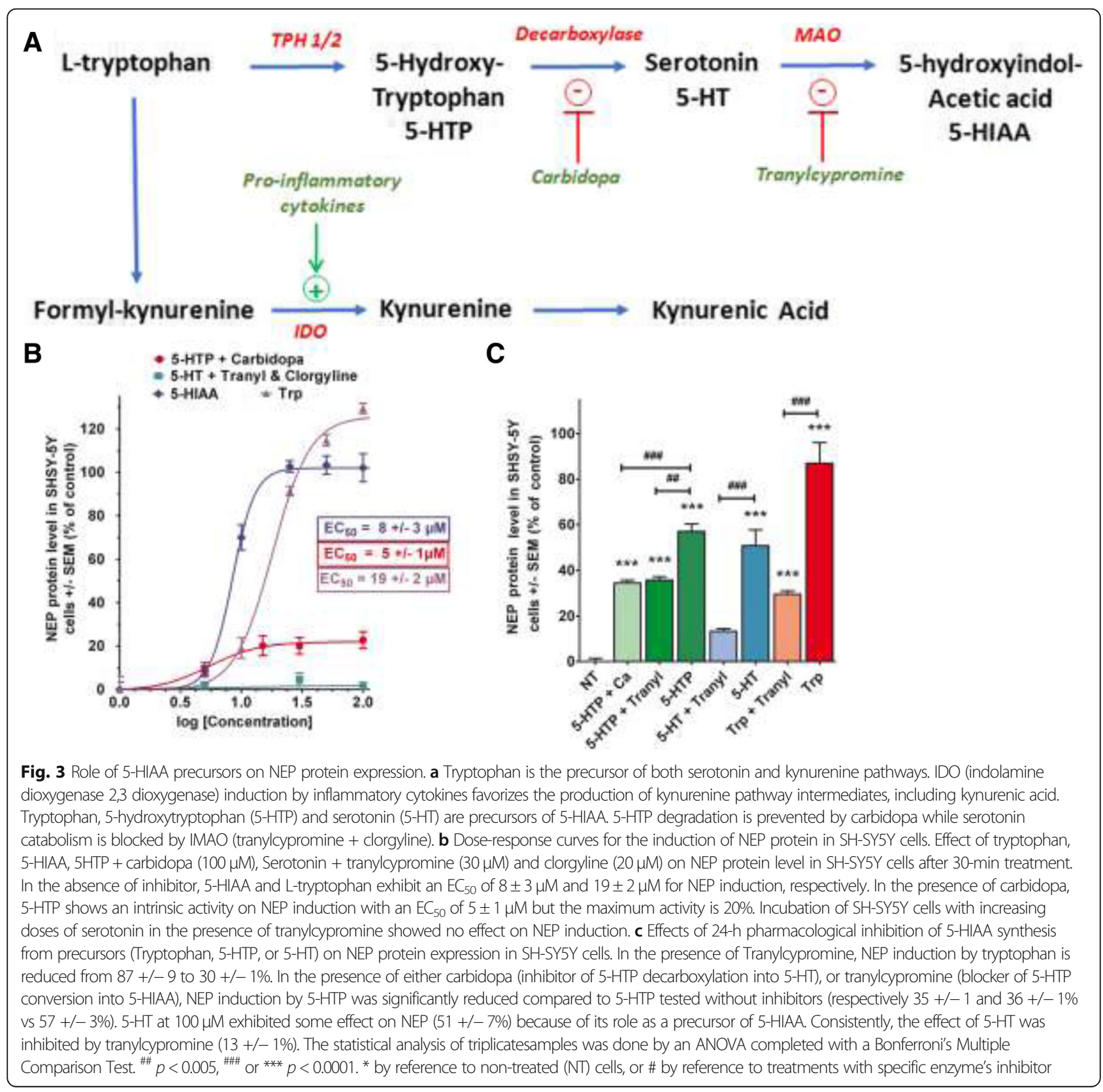


Table 2 Variations of brain amyloid peptide level in APPSWE and WT mice after 5-HIAA or 5-HTP treatment

\begin{tabular}{|c|c|c|c|c|c|c|}
\hline & WT NT & WT 5HIAA & $\operatorname{Tg} N T$ & $\operatorname{Tg} 5 \mathrm{HIAA}$ & Tg 5HTP & \\
\hline \multirow[t]{3}{*}{$A \beta 40$} & 109.2 & 88.6 & 3285 & 1996 & 1031 & Mean (pg/total proteins) \\
\hline & 100 & 81 & 100 & 61 & 31 & Mean compared with NT (\%) \\
\hline & 0 & -19 & 0 & -39 & -69 & $\begin{array}{l}\% \text { of variation compared to } \\
\text { corresponding NT }\end{array}$ \\
\hline \multirow[t]{3}{*}{$A \beta 42$} & 25.2 & 15.3 & 2544 & 2192 & 1408 & Mean (pg/total proteins) \\
\hline & 100 & 61 & 100 & 86 & 55 & Mean compared with NT (\%) \\
\hline & 0 & -39 & 0 & -14 & -45 & $\begin{array}{l}\% \text { of variation compared to } \\
\text { corresponding NT }\end{array}$ \\
\hline
\end{tabular}

5-HIAA in SH-SY5Y incubation medium to confirm the role of ERK pathway inhibition in the neo-expression of NEP. As shown in Fig. 4b, NEP protein expression is strongly stimulated by the presence of SCH772984 after $90 \mathrm{~min}$ of incubation and the addition of $100 \mu \mathrm{M}$ 5-HIAA increases this stimulation significantly. Similarly, the MEK inhibitor (GSK 1120212, Trametinib) which plays a role as a MEK/MAPK/ERK kinase inhibitor, induces NEP with an $\mathrm{EC}_{50}$ in the nanomolar range. These results constitute additional evidence for a role of MAP-kinase cascade in NEP expression mediated by 5-HIAA. However, as several reports described a role for AICD peptide (intra-cellular domain of APP) in the control of NEP expression [18], this possibility was tested in the same experimental model. While $\mathrm{NH}_{4} \mathrm{Cl}$ strongly induced AICD, this peptide was down-regulated by 5-HIAA, suggesting that the mechanism activated by 5-HIAA to induce NEP expression does not involve or depend on AICD stimulation (Fig. 4c).

\section{Discussion and conclusions}

In its early stage of clinical expression, sporadic AD is heterogeneous with cognitive, behavioral or psychological symptoms of many kinds, including alterations of mood, emotive disorders, confusion, agitation and anxiety or modifications in the sleep-wake cycle [46]. Serotonin and its brain innervations are known to modulate these alterations and pharmacological manipulations of the serotonergic system have long been used as therapeutic approach for these symptoms [11]. This therapeutic strategy includes the potentiation of serotonin synthesis by tryptophan or 5-HTP administration, the inhibition of serotonin transport by SSRI's or degradation by IMAO. Among the large family of serotonergic receptors (5-HT1 to 5-HT7, each of them containing several isoforms), several classes appear to be implicated in AD related mechanisms. 5-HT2 receptors (2A, 2B, 2C) which activate phospholipase $\mathrm{C}$ pathway and 5-HT4, 5-HT6 that are coupled to Gs, have been reported to regulate the proteolytic cleavage of APP, neuroinflammation and cognitive deficits. The mechanisms involved in these processes are unknown, and serotonin is supposed to activate the complete set of its receptors with a global effect to be defined regarding AD [24]. This disease is characterized by diffuse brain atrophy due to neuronal degeneration and synaptic loss affecting multiple regions in the brain. The neurodegeneration results from $\mathrm{A} \beta$ accumulation and hyperphosphorylation of Tau which affect neuron survival [9]. Interestingly, it has been shown that the dorsal raphe nucleus exhibits cytoskeletal lesions at early stages of the disease, suggesting a possible role for the ascending serotonergic pathway in early manifestations of $\operatorname{AD}[5,19,43]$. Amyloid protein accumulation in the brain is a prolonged process induced by chronic inflammation, reduction of energy metabolism and promotion of apoptotic mechanisms which precede the development of microtubule-associated protein Tau hyperphosphorylation and loss of functions [13]. Several mutations and gene variants are in favor of a closed link between $A \beta$ proteinopathy and progressive occurrence of dementia in $\mathrm{AD}[1,42]$. The accumulation of amyloid oligomers is tightly regulated in the normal brain, in part by a fine control of their clearance. The cellular proteolysis of many brain proteins involves the proteasome and the lysosome, but also many proteolytic activities including Insulin-degrading enzyme, Endothelin or angiotensin converting enzyme and matrix metalloproteinases among others $[33,56]$. However, a pivotal role is assigned to NEP, a cell-surface ectoenzyme degrading several key neuropeptides (enkephalins, substance $\mathrm{P})$, which has been identified as a major $\mathrm{A} \beta$ degrading enzyme in the brain. Over-expression of NEP in Drosophila or in transgenic mice could suppress amyloid plaques formation or reduce brain $A \beta$ levels. By contrast, a reduction of NEP expression has been evidenced in the brain of aged or AD patients [23, 33]. However, NEP activity seems to be stimulated in brain cells in contact with amyloid deposits in human brain. It appears that NEP up-regulation could be an adaptive mechanism counteracting brain $A \beta$ accumulation and protecting thus neuron survival during the disease incubation [40]. Since several years, a pharmacological approach has been suggested to increase NEP activity in the brain and several compounds were identified as NEP expression modulators, some of them being potential actors regulating NEP homeostasis in vivo [28, 


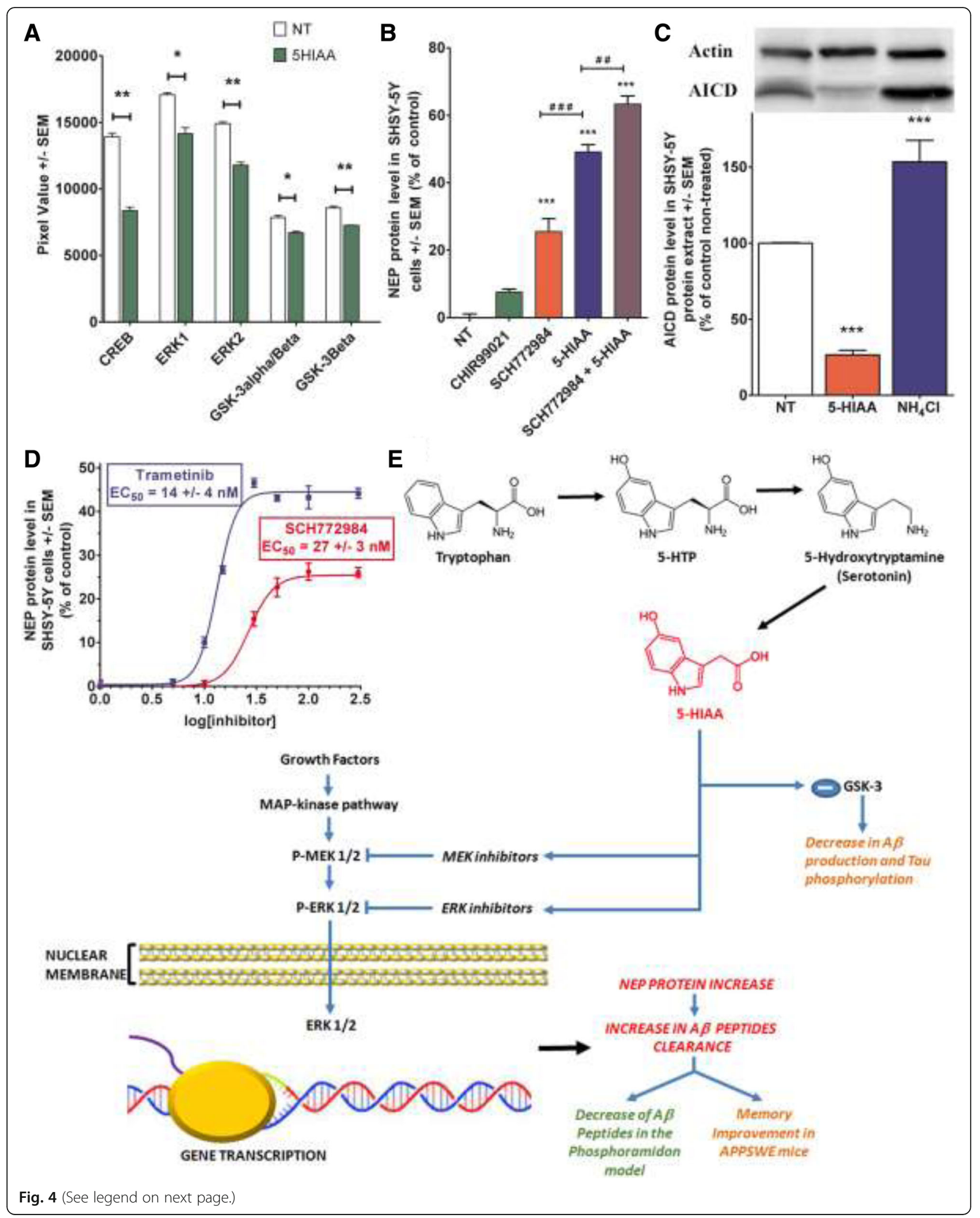




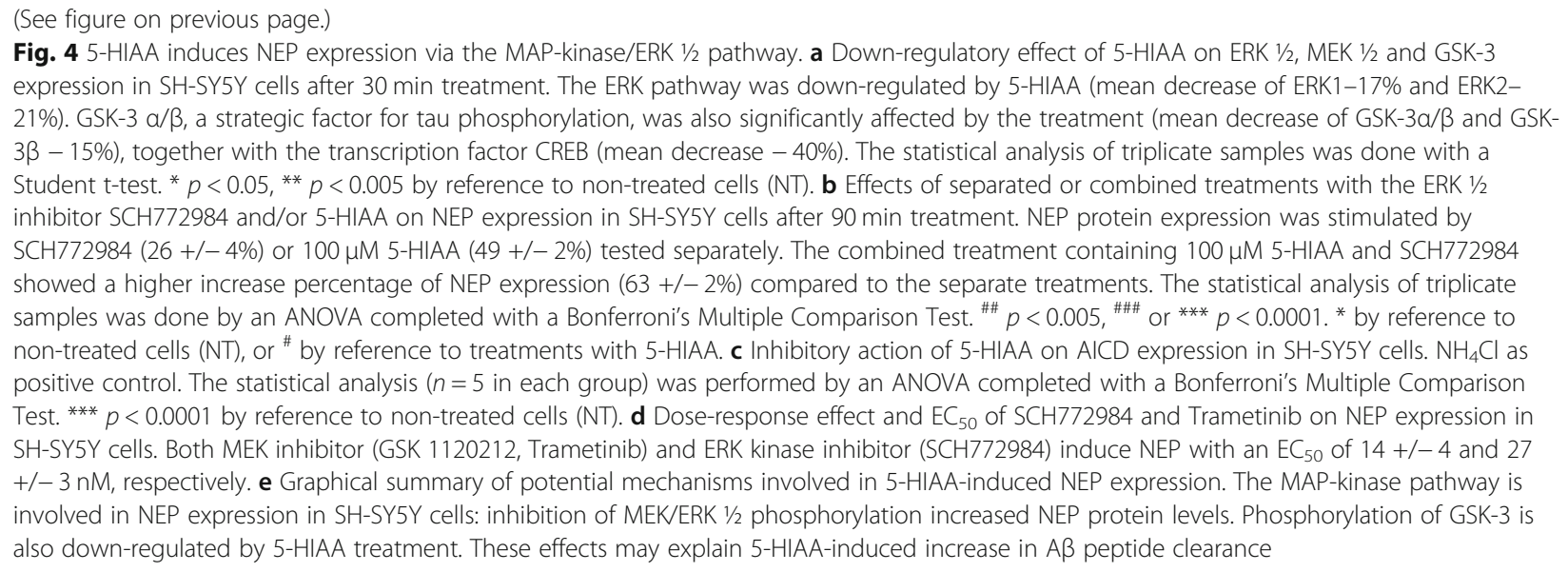

$29,34,51]$. The fundamental interest of these studies is to try to slow-down the occurrence of AD clinical symptoms and beneficial effects against memory deficits have been reported in animal models following NEP up-regulation.

The present work describes the role of 5-HIAA, the final product of serotonin metabolism, as an inducer of NEP expression in the brain. This compound is not a ligand for serotonin receptors and was until now considered only as a dead-end product, with no functional role. However, 5-HIAA was implicated recently in the negative control of RAS/MAPK signaling pathway in C. elegans [45]. Interestingly, NT-3 treatment significantly increased A $\beta$ in primary neuron cultures, an effect which was abolished by the MEK 1/2 inhibitor UO126 [25]. The Ras/MAP-kinases pathway was reported to be elevated in initial stages of $\mathrm{AD}$, before the accumulation and pathology driven by $\mathrm{A} \beta$ $[15,16]$. A pathological link between $A \beta$ generation and altered MAP/phospho-ERK signaling seems to exist. Phospho-ERK contributes to tau phosphorylation but GSK-3 is also involved in this process, together with several other kinases [27]. GSK-3 promotes every major pathological process in $\mathrm{AD}$, including apoptosis and GSK-3 inhibitors improve several cognitive functions in transgenic mice models for $\mathrm{AD}$ [4]. We demonstrate that in SH-SY5Y cell cultures, 5-HIAA-induced neo-expression of NEP protein and this effect is partially reproduced by the inhibition of ERK 1/2 pathway. 5-HIAA reduces also the expression of GSK-3 and this action may additionally ameliorate AD symptoms in APPSWE transgenic mice. Moreover, P-CREB decrease observed after 5-HIAA administration may probably result from the down-regulation of MAP-kinase/GSK-3 pathways but it is difficult to estimate the direct impact of this effect on the behavior of APPSWE mice owing to the involvement of P-CREB in various events related to brain plasticity [7].

Independently from the effect of 5-HIAA on NEP gene expression, its possible inhibitory action at the hamster prion promoter controlling the mutated human APP isoform expression in APPSWE mice is worthy of attention. 5-HIAA may act via this mechanism to reduce mutated APP expression and decrease $A \beta$ accumulation in APPSWE mice. However, the probability of such action appears extremely low since the removal of $\operatorname{PrP}^{\mathrm{C}}$ prion from human APP-transgenic mice did not modify APP proteolysis, $A \beta$ levels or pathologic phenotype [55].

Consistently, we observed that 5-HIAA increased NEP expression and decreased brain $A \beta$ in the mouse model of intranasal phosphoramidon-induced NEP inhibition and cerebral accumulation of amyloid oligomers [21]. However, besides NEP inhibition, phosphoramidon may also reduce the activity of other $A \beta$ degrading enzymes including the endothelin-converting enzyme [14]. Therefore, the possibility that in addition to NEP induction, 5-HIAA may also promote the activity of other $A \beta$ degrading enzymes cannot be ruled out. Moreover, it has been reported that intracerebroventricular injection of the protease inhibitor phosphoramidon into wild type mice increased brain $A \beta$ deposits and concomitantly induced neurodegeneration of hippocampal neurons and neuroinflammation [37]. Interestingly, we found that in the transgenic mouse model of AD expressing a human-mutated APP (APP Swedish) and accumulating brain $A \beta$, in vivo administration of 5-HIAA treatment during 5 consecutive days significantly reduced brain $A \beta$ concentration and counteracted memory deficits in a spatial recognition task. The possibility exists that a longer period of treatment could induce a deeper elimination of $A \beta$, since there is no obvious toxicity of 5-HIAA. However, as the intra-nasal route was used to circumvent the blood brain barrier, this mode of administration may have some limitations for very long-term therapies. Therefore, a possibility could be the use of precursors of 5-HIAA such as tryptophan or 5-HTP that can be absorbed per os. Serotonin is also degraded into 5-HIAA in vitro and the global activity of the serotonergic system influences 5-HIAA levels in vivo. Thus, we explored a possible effect of these three substances using 
pharmacological treatment of SH-SY5Y neuronal cultures. We found that tryptophan, 5-HTP and serotonin induce NEP and these effects were strongly reduced by the presence of carbidopa or pargyline which inhibits dopa-decarboxylase or MAO, respectively. Thus, these three substances appear to act on NEP protein levels via the synthesis of 5-HIAA. For tryptophan, whose dietary increase reduces intraneuronal $A \beta$ density in transgenic animals [32], the blockade of its degradation into 5-HIAA by MAO inhibition strongly reduced its ability to induce NEP synthesis. But tryptophan is the precursor of both kynurenine and serotonin pathways, and chronic inflammation is thought to drive tryptophan metabolism into the kynurenine pathway after induction of indolamine 2,3-dioxygenase, in detriment of serotonin metabolism [30]. A role of some intermediates of kynurenine pathway has been described in the pathophysiology of neurodegenerative diseases, including $\mathrm{AD}[6,31]$. Concerning 5 -HTP, a direct precursor of both serotonin and 5-HIAA, the inhibition of dopa-decarboxylase decreases its effect on NEP induction, but this compound has also a direct role on NEP protein levels in cell cultures with an $\mathrm{EC}_{50}$ of about $5 \mu \mathrm{M}$.

The role of serotonin appears more complex. The synthesis of serotonin is associated with lower $A \beta$ levels in animals and humans [10]. In the presence of a MAO inhibitor, the stimulatory effect of serotonin on NEP protein in cell cultures disappeared, indicating that the reported beneficial effect of serotonin on $A \beta$ levels is partly due to its catabolism into 5-HIAA. Serotonin itself has no effect on NEP but this neurotransmitter has been reported to exert several beneficial effects on $\mathrm{AD}$ via other mechanisms, as demonstrated by the pharmacological action of some SSRI and agonists/antagonists at 5-HT receptors [47]. Moreover, it is well demonstrated that the raphe nuclei are affected by neurofibrillary tangles very early in $\mathrm{AD}$ pathogenesis, suggesting the occurrence of early serotoninergic alterations that may facilitate $\mathrm{AD}$ progression $[5,19,43]$. Therefore, our results showing a beneficial role and mechanisms of action of serotonin metabolite 5-HIAA (until now considered only as a dead-end inactive product) in a mouse model of $\mathrm{AD}$, may contribute to improve the efficacy of serotoninergic derivatives-based strategies against $\mathrm{AD}$.

In conclusion, the present report, which provides the first demonstration that 5-HIAA sub-chronic therapy actively increases brain $A \beta$ degradation/clearance and ameliorates symptoms in the APPSWE mouse model for $\mathrm{AD}$, also contributes to elucidate the role of tryptophan/ kynurenine/serotonin interrelated pathways in $\mathrm{AD}$ pathophysiology and progression.

\section{Abbreviations}

5-HIAA: 5-hydroxyindolacetic acid; APPSWE: Transgenic mice, B6; ERK 1/2: Extracellular signal-regulated kinases; GSK-3: Glycogen synthase kinase-3; MEK 1/2: Mitogen extracellular signal-regulated kinases; NEP: Neprilysin; SJLTg: (APPSWE) 2576Kha

\section{Acknowledgements}

This work was supported by grants from Institut National de la Santé et de la Recherche Médicale (INSERM, France) and Université de Strasbourg (France). Additional support was provided by the NeuroRhine Consortium coordinated by AGMN and funded by INTERREG IV Program (European Fund for Regional Development) in the Upper Rhine Region and the Offensive Science Call 2012. Authors would like to thank Dr. Martine Schmitt for the chemical advices.

\section{Authors' contributions}

CK performed biochemical, cell cultures and behavioral studies and analyzed the data. GR performed immunocytochemical studies and microscope analysis. SB performed flow cytometry analysis. CR participated to cell culture studies. CPM contributed to the design of the research project, supervised biochemical, cell culture studies and analyzed the data. MM and AGMN designed the whole research project, supervised all the studies, analyzed the data and wrote the manuscript. All authors read and approved the final manuscript.

\section{Competing interests}

The authors declare that they have no competing interests.

\section{Publisher's Note}

Springer Nature remains neutral with regard to jurisdictional claims in published maps and institutional affiliations.

Received: 25 October 2018 Accepted: 28 November 2018

Published online: 11 December 2018

\section{References}

1. Bagyinszky E, Youn YC, An SS, Kim S (2014) The genetics of Alzheimer's disease. Clin Interv Aging 9:535-551

2. Baranello RJ, Bharani KL, al PV (2015) Amyloid-beta protein clearance and degradation $(A B C D)$ pathways and their role in Alzheimer's disease. Curr Alzheimer Res 12:32-46

3. Benosman S, Gross I, N C et al (2007) Multiple neurotoxic stresses converge on MDMX proteolysis to cause neuronal apoptosis. Cell Death Differ 14: 2047-2057

4. Beurel E, Grieco SF, Jope RS (2015) Glycogen synthase kinase-3 (GSK3): regulation, actions, and diseases. Pharmacol Ther 148:114-131

5. Braak H, Thal DR, Ghebremedhin E, Del Tredici K (2011) Stages of the pathologic process in Alzheimer disease: age categories from 1 to 100 years. J Neuropathol Exp Neurol 70:960-969

6. Breda C, Sathyasaikumar KV, Sograte Idrissi S et al (2016) Tryptophan-2,3dioxygenase (TDO) inhibition ameliorates neurodegeneration by modulation of kynurenine pathway metabolites. Proc Natl Acad Sci U S A 113:5435-5440

7. Carlezon WA Jr, Duman RS, Nestler EJ (2005) The many faces of CREB. Trends Neurosci 28:436-445

8. Chaikuad A, Tacconi EM, Zimmer J et al (2014) A unique inhibitor binding site in ERK1/2 is associated with slow binding kinetics. Nat Chem Biol 10: $853-860$

9. Chiti F, Dobson CM (2017) Protein Misfolding, amyloid formation, and human disease: a summary of Progress over the last decade. Annu Rev Biochem 86:27-68

10. Cirrito JR, Disabato BM, Restivo $J$ et al (2011) Serotonin signaling is associated with lower amyloid-beta levels and plaques in transgenic mice and humans. Proc Natl Acad Sci U S A 108:14968-14973

11. Claeysen S, Bockaert J, Giannoni P (2015) Serotonin: a new Hope in Alzheimer's disease? ACS Chem Neurosci 6:940-943

12. Cooper-Knock J, Kirby J, Ferraiuolo L, Heath PR, Rattray M, Shaw PJ (2012) Gene expression profiling in human neurodegenerative disease. Nat Rev Neurol 8:518-530

13. Doyle KM, Kennedy D, Gorman AM, Gupta S, Healy SJ, Samali A (2011) Unfolded proteins and endoplasmic reticulum stress in neurodegenerative disorders. J Cell Mol Med 15:2025-2039

14. Eckman EA, Reed DK, Eckman CB (2001) Degradation of the Alzheimer's amyloid beta peptide by endothelin-converting enzyme. J Biol Chem 276: 24540-24548 
15. Gartner U, Holzer M, Arendt T (1999) Elevated expression of p21ras is an early event in Alzheimer's disease and precedes neurofibrillary degeneration. Neuroscience 91:1-5

16. Gartner U, Holzer M, Heumann R, Arendt T (1995) Induction of p21ras in Alzheimer pathology. Neuroreport 6:1441-1444

17. Good MA, Hale G (2007) The "Swedish" mutation of the amyloid precursor protein (APPswe) dissociates components of object-location memory in aged Tg2576 mice. Behav Neurosci 121:1180-1191

18. Grimm MO, Mett J, Stahlmann CP et al (2015) APP intracellular domain derived from amyloidogenic beta- and gamma-secretase cleavage regulates neprilysin expression. Front Aging Neurosci 7:77

19. Grinberg LT, Rub U, Ferretti RE et al (2009) The dorsal raphe nucleus shows phospho-tau neurofibrillary changes before the transentorhinal region in Alzheimer's disease. A precocious onset? Neuropathol Appl Neurobiol 35:406-416

20. Hanson LR, Fine JM, Svitak AL, Faltesek KA (2013) Intranasal administration of CNS therapeutics to awake mice. J Vis Exp. https://doi.org/10.3791/4440

21. Hanson LR, Hafez D, Svitak AL et al (2011) Intranasal phosphoramidon increases beta-amyloid levels in wild-type and NEP/NEP2-deficient mice. J Mol Neurosci 43:424-427

22. Hsiao K, Chapman P, Nilsen S et al (1996) Correlative memory deficits, Abeta elevation, and amyloid plaques in transgenic mice. Science 274:99-102

23. lijima-Ando K, lijima K (2010) Transgenic Drosophila models of Alzheimer's disease and tauopathies. Brain Struct Funct 214:245-262

24. Jankowska A, Wesolowska A, Pawlowski M, Chlon-Rzepa G (2017) Multitarget-directed ligands affecting serotonergic neurotransmission for Alzheimer's disease therapy: advances in chemical and biological research. Curr Med Chem 25:2045-2067

25. Kakiya N, Saito T, Nilsson P et al (2012) Cell surface expression of the major amyloid-beta peptide (Abeta)-degrading enzyme, neprilysin, depends on phosphorylation by mitogen-activated protein kinase/extracellular signalregulated kinase kinase (MEK) and dephosphorylation by protein phosphatase 1a. J Biol Chem 287:29362-29372

26. Kerridge C, Belyaev ND, Nalivaeva NN, Turner AJ (2014) The Abeta-clearance protein transthyretin, like neprilysin, is epigenetically regulated by the amyloid precursor protein intracellular domain. J Neurochem 130:419-431

27. Kirouac L, Rajic AJ, Cribbs DH, Padmanabhan J (2017) Activation of Ras-ERK signaling and GSK-3 by amyloid precursor protein and amyloid Beta facilitates neurodegeneration in Alzheimer's disease. eNeuro 4. https://doi. org/10.1523/ENEURO.0149-16.2017

28. Klein C, Mathis C, Leva G et al. (2015) Gamma-Hydroxybutyrate (Xyrem) ameliorates clinical symptoms and neuropathology in a mouse model of Alzheimer's disease. Neurobiol Aging 36: 832-844

29. Klein C, Patte-Mensah C, Taleb O et al (2013) The neuroprotector kynurenic acid increases neuronal cell survival through neprilysin induction. Neuropharmacology 70:254-260

30. Lovelace MD, Varney B, Sundaram G et al (2017) Recent evidence for an expanded role of the kynurenine pathway of tryptophan metabolism in neurological diseases. Neuropharmacology 112:373-388

31. Maddison DC, Giorgini F (2015) The kynurenine pathway and neurodegenerative disease. Semin Cell Dev Biol 40:134-141

32. Musumeci G, Castrogiovanni P, Szychlinska MA et al (2017) Protective effects of high tryptophan diet on aging-induced passive avoidance impairment and hippocampal apoptosis. Brain Res Bull 128:76-82

33. Nalivaeva NN, Beckett C, Belyaev ND, Turner AJ (2012) Are amyloiddegrading enzymes viable therapeutic targets in Alzheimer's disease? J Neurochem 120(Suppl 1):167-185

34. Nalivaeva NN, Belyaev ND, Lewis DI et al (2012) Effect of sodium valproate administration on brain neprilysin expression and memory in rats. J Mol Neurosci 46:569-577

35. Nalivaeva NN, Belyaev ND, Turner AJ (2016) New insights into epigenetic and pharmacological regulation of amyloid-degrading enzymes. Neurochem Res 41:620-630

36. Nilsson P, Loganathan $K$, Sekiguchi M et al (2015) Loss of neprilysin alters protein expression in the brain of Alzheimer's disease model mice. Proteomics 15:3349-3355

37. Nisemblat Y, Belinson H, Dolev I, Michaelson DM (2008) Activation of the amyloid cascade by intracerebroventricular injection of the protease inhibitor phosphoramidon. Neurodegener Dis 5:166-169

38. Ognibene E, Middei S, Daniele S et al (2005) Aspects of spatial memory and behavioral disinhibition in Tg2576 transgenic mice as a model of Alzheimer's disease. Behav Brain Res 156:225-232
39. Pacheco-Quinto J, Eckman CB, Eckman EA (2016) Major amyloid-betadegrading enzymes, endothelin-converting enzyme-2 and neprilysin, are expressed by distinct populations of GABAergic interneurons in hippocampus and neocortex. Neurobiol Aging 48:83-92

40. Park MH, Lee JK, Choi S et al (2013) Recombinant soluble neprilysin reduces amyloid-beta accumulation and improves memory impairment in Alzheimer's disease mice. Brain Res 1529:113-124

41. Piaceri I, Nacmias B, Sorbi S (2013) Genetics of familial and sporadic Alzheimer's disease. Front Biosci (Elite Ed) 5:167-177

42. Rosenberg RN, Lambracht-Washington D, Yu G, Xia W (2016) Genomics of Alzheimer disease: a review. JAMA Neurol 73:867-874

43. Rub U, Del Tredici K, Schultz C, Thal DR, Braak E, Braak H (2000) The evolution of Alzheimer's disease-related cytoskeletal pathology in the human raphe nuclei. Neuropathol Appl Neurobiol 26:553-567

44. Saito T, Iwata N, Tsubuki S et al (2005) Somatostatin regulates brain amyloid beta peptide Abeta42 through modulation of proteolytic degradation. Nat Med 11:434-439

45. Schmid T, Snoek LB, Frohli E, van der Bent ML, Kammenga J, Hajnal A (2015) Systemic regulation of RAS/MAPK signaling by the serotonin metabolite 5HIAA. PLoS Genet 11:e1005236

46. Simic G, Babic Leko M, Wray S et al (2017) Monoaminergic neuropathology in Alzheimer's disease. Prog Neurobiol 151:101-138

47. Smith GS, Barrett FS, Joo JH et al (2017) Molecular imaging of serotonin degeneration in mild cognitive impairment. Neurobiol Dis 105:33-41

48. Stroo E, Koopman M, Nollen EA, Mata-Cabana A (2017) Cellular regulation of amyloid formation in aging and disease. Front Neurosci 11:64

49. Tentolouris-Piperas V, Ryan NS, Thomas DL, Kinnunen KM (2017) Brain imaging evidence of early involvement of subcortical regions in familial and sporadic Alzheimer's disease. Brain Res 1655:23-32

50. Vermeiren Y, Van Dam D, Aerts T, Engelborghs S, De Deyn PP (2014) Monoaminergic neurotransmitter alterations in postmortem brain regions of depressed and aggressive patients with Alzheimer's disease. Neurobiol Aging 35:2691-2700

51. Wang Z, Zhang XJ, Li T, Li J, Tang Y, Le W (2014) Valproic acid reduces neuritic plaque formation and improves learning deficits in APP(Swe) /PS1(A246E) transgenic mice via preventing the prenatal hypoxia-induced down-regulation of neprilysin. CNS Neurosci Ther 20:209-217

52. Weiner MW, Veitch DP, al APS (2017) Recent publications from the Alzheimer's disease neuroimaging initiative: reviewing progress toward improved AD clinical trials. Alzheimer's Dement 13:e1-e85

53. Wendt G, Kemmel V, Patte-Mensah C et al (2014) Gamma-hydroxybutyrate, acting through an anti-apoptotic mechanism, protects native and amyloidprecursor-protein-transfected neuroblastoma cells against oxidative stressinduced death. Neuroscience 263:203-215

54. Westerman MA, Cooper-Blacketer D, Mariash A et al (2002) The relationship between Abeta and memory in the Tg2576 mouse model of Alzheimer's disease. J Neurosci 22:1858-1867

55. Whitehouse IJ, Brown D, Baybutt $\mathrm{H}$ et al (2016) Ablation of prion protein in wild type human amyloid precursor protein (APP) transgenic mice does not Alter the proteolysis of APP, levels of amyloid-beta or pathologic phenotype. PLoS One 11:e0159119

56. Whyte LS, Lau AA, Hemsley KM, Hopwood JJ, Sargeant TJ (2017) Endolysosomal and autophagic dysfunction: a driving factor in Alzheimer's disease? J Neurochem 140:703-717

57. Yassine N, Lazaris A, Dorner-Ciossek C et al (2013) Detecting spatial memory deficits beyond blindness in tg2576 Alzheimer mice. Neurobiol Aging 34: $716-730$

\section{Ready to submit your research? Choose BMC and benefit from}

- fast, convenient online submission

- thorough peer review by experienced researchers in your field

- rapid publication on acceptance

- support for research data, including large and complex data types

- gold Open Access which fosters wider collaboration and increased citations

- maximum visibility for your research: over $100 \mathrm{M}$ website views per year

At $\mathrm{BMC}$, research is always in progress.

Learn more biomedcentral.com/submission 